\title{
Bevacizumab Regimen
}

National Cancer Institute

\section{Source}

National Cancer Institute. Bevacizumab Regimen. NCI Thesaurus. Code C159998.

An immunotherapy regimen consisting of bevacizumab that may be used in the treatment of soft tissue and AIDS-related Kaposi sarcomas; anaplastic gliomas and glioblastomas; adult intracranial and spinal ependymomas (excluding subependymomas and myxopapillary ependymomas); and kidney, cervical, endometrial, ovarian/fallopian tube/primary peritoneal and non-small cell lung cancers (NSCLCs) 